\title{
Prediction of Space Heating Energy Consumption in Cabins Based on Multivariate Regression Modelling
}

\author{
D. Wathsala Upamali Perera, Maths Halstensen, and Nils-Olav Skeie
}

\begin{abstract}
There is a growing interest in reducing energy consumption in buildings. The residential building sector is a substantial energy consumer in many countries. Since the energy consumption characteristics of the residential sector are complex, different types of models are investigated by the researchers to assess the performance. Statistical techniques such as multivariate regression correlate the energy-related measures with the influencing variables. Partial Least Squares Regression (PLSR) is an attractive tool for analyzing complex and large data sets related to building energy optimization because it can handle the dimensionality, correlations and noise present in the building related multi-variable problems.

This work is about developing a PLSR model that can predict the space heating energy usage of a cabin with respect to ambient weather conditions. The weather conditions have a great influence on the energy performance of buildings. The model predicts the energy consumption with a RMSEP of 0.23 in hourly basis. The results showed that variations in energy consumption could be predicted accurately. Furthermore, the model interpretation identified the most influential parameters such as outdoor temperature and indoor relative humidity.

The development of reliable and fast mathematical models to predict the space heating energy usage is beneficial because they can be integrated with Building Energy Management Systems (BEMS). The developed PLSR model fulfills the criteria and can be combined with BEMS and similarly can be combined with a dynamic model of the building to estimate the heating time.
\end{abstract}

Index Terms-Cabins, energy consumption, multivariate regression, space heating, weather variables.

\section{INTRODUCTION}

World energy consumption is rapidly growing, and there are raised concerns over supply difficulties, exhaustion of energy resources and heavy environmental impacts. The final energy consumption can be split into three sections: (i) industry; (ii) transport and; (iii) other [1]. The third section mainly encompasses of agriculture, service sector and residential which mainly comprises of buildings. The final energy consumption in the building sector has been increasing owing to the growth in population, enhancement of building services and comfort levels together with the rise in time spent inside the buildings. Because of these reasons, building energy consumption has risen to the levels of

Manuscript received October 10, 2015; revised December 10, 2015. This work was supported by the Telemark University College, Porsgrunn, Norway.

D. Wathsala Perera is with Telemark University College, Porsgrunn, Norway (e-mail: wathsala.perera@hit.no).

Maths Halstensen and Nils-Olav Skeie are with the Department of Electrical, IT and Cybernetics, Telemark University College, Porsgrunn, Norway (e-mail: Maths.Halstensen@hit.no, Nils-Olav.Skeie@hit.no). transport and industry. The energy consumption of major sectors such as commercial, industrial, agriculture and transportation are better understood than the residential sector owing to their more centralized ownership, self-interest, expertise in reducing energy consumption and high levels of regulation and documentation [2]. However, the residential sector is an undefined energy sink owing to wide variety of structure sizes, geometries and envelope materials, wide occupant behaviours, privacy issues in collection and distribution of energy data and the cost of detailed sub-metering of household end-uses [2]. The major energy end-use applications in residential buildings are: space heating and space cooling; domestic hot water and; appliances and lighting [2]. The degree to which these groups affect the overall energy consumption is highly dependent on the climate conditions, physical characteristics of the dwelling, appliance and system characteristics, ownership and occupant behaviour [2].

The average energy consumption of the world residential building sector is approximately $30 \%$ out of the total global energy consumption [2]. In 2004, building energy consumption in the European Union was 37\% of the total energy, which has now increased to $40 \%$. Out of that, $63 \%$ is utilized in residential buildings [3]. Energy consumption by end-use in EU-15 member states is dominated by space heating (70\%) [3]. The prediction of energy consumption of buildings is, therefore, significant in order to improve their energy performance with the aim of achieving energy conservation and reducing environmental impact related to $\mathrm{CO}_{2}$ emissions.

In Norway, $21 \%$ of the national energy production is consumed in residential buildings [2]. Norwegians experience harsh climate conditions owing to predominating low temperatures during about one-third of the year. It makes the energy consumption of buildings to rise rapidly during cold winter periods. To ensure the thermal comfort of the occupants and to avoid freezing of water sources it is important to heat the buildings. An important aspect here is even when the building is not occupied, it is necessary to heat the building to a certain temperature to ensure the water sources are not affected. However, the Norwegian household energy consumption has fallen from approximately 210 $\mathrm{kWh} / \mathrm{m}^{2}$ in the early $1990 \mathrm{~s}$ to approximately $180 \mathrm{kWh} / \mathrm{m}^{2}$ in 2012 [4]. The prime cause of this drop is the improvements to existing housing and better quality of new housing as of more stringent energy requirements in the new building regulations like TEK10 (Norwegian Building Code issued in 2010) [5]. Meanwhile, it is important to note that the space heating energy consumption has a higher contribution in the total household energy consumption and the relevant percentage is 
increasing. In that case, Norway needs better heating control systems and opportunely, at present there is a trend towards better systems.

Building Energy Management Systems (BEMS) are recently gaining attention as a decent building control system [6]. These systems are currently operating with classical control algorithms such as on-off control, PID control and optimal start-stop routines. Thermal interaction between different zones of building and HVAC (Heating, Ventilation and Air-Conditioning) systems leads to a multi-variate behavior, which cannot be accurately controlled with classical control techniques [6]. Thus, advanced control systems that can handle multiple inputs - multiple outputs is a better approach to control buildings [6], [7], [8]. Integration of mathematical models that can describe the building physics may help for a successful control of building energy efficiency. Mathematical models to be combined can be either dynamic, static or grey type. The dynamic models use physical principles of mass, energy and momentum to calculate the thermal dynamics and energy behaviour of a building. They are more general and can be adapted to any building. Statistical regression models correlate the energy consumption with the influencing variables. These models are more specific and can only be applied to the building where the data is collected. Grey models combine dynamic and static models. Statistical modelling methods such as multivariate analysis can be a valuable support for controlling the energy with respect to weather conditions, physical characteristics and operating conditions.

In literature, occasions can be found where multivariate analysis has been used to estimate the energy use of buildings. In some applications, the regression modeling is used to correlate energy consumption with the climate variables to obtain an energy signature [9]-[11]. Bauer and Scartezzini [9] proposed a regression method to handle heating and cooling calculations by dealing with internal gains and solar gains. Pfafferott et al. [10] have used data to identify the correlation between outdoor and indoor temperature in a building under ordinary use and to derive the energy balance of an office room. Regression is used by Westergren et al. [11] to determine the average annual energy use against climate data. Braun et al. [12] has carried out a regression analysis to predict the future energy consumption of a supermarket based on the temperature and relative humidity. The gas and electricity consumption of the supermarket are the target energy measures of the study. Multiple regression methods for energy use in office buildings in different climate conditions have been studied in [13], [14]. Partial Least Squares Regression (PLSR) can be applied to analyse the building systems data to overview the energy related matters. It has the capability to address the complexity present in the building heating systems. PLSR has been used by Djuric and Novakovic and Olofsson et al. to estimate the energy use of buildings [15], [16]. The study in [15] aims to identify driving variables of energy utilization in a low energy office building located in Trondheim, Norway by integrating BEMS and energy usage data. They have related building information with the building energy consumption using multivariate data analysis techniques such as Principal Component Regression (PCR) and PLSR. The results show that the significant variables are different for different months in the case of heating energy use. Further, heating energy consumption is influenced by operational parameters rather than by outside temperature for an office building. They stated that PLSR method was more accurate in recovering the heating energy use. The investigation carried out by [16] uses a multivariate PLSR method to model different energy performance measures such as energy management for heating. In this work, data of 112 comparable multifamily buildings located in Stockholm area are used. Monthly consumption data together with a large number of building specific classification parameters are used for the analysis.

There are several simulation tools exist for analyzing the energy performance of buildings. Energy Plus, TRNSYS, DOE-2 and ESP-r like tools are specifically developed for building performance simulations. More generic programs such as MATLAB/SIMULINK, C, C\#, Java, Phyton and Modelica are also available for the same purpose. For a model to be suitable for on-line control applications, it should provide the desired accuracy in a short execution time, possibly within few minutes. Most of the mechanistic building heating models that are developed using special building software tools are highly accurate with a high computational burden, making them not suitable for on-line control. To overcome this issue, simple and fast mechanistic models are developed in the MATLAB environment by the author with acceptable accuracy [5], [7]. At the moment, these mechanistic models use MATLAB loops to model the on-off controlled heaters in the buildings which make them complex to some extent. Use of a multivariate regression model to feed the pattern of power consumption based on weather conditions is a good option to further reduce the response time of the mechanistic model. Since the application of regression models is straightforward and fast, it can be integrated with the dynamic model in control applications to obtain better results.

The available weather and operating data relevant to buildings may mislead without an overview or sense of direction in order to improve the building energy performance. One reason for this conception might be the incompetence of conventional univariate methods to analyze data sets with a large number of variables [17]. Conversely, multivariate techniques are not as prone to fail with complicated data structures [17], [18]. In fact, multivariate methods such as PLSR are ideally suited for the analysis of complicated data because they can overwhelm the intrinsic problems related to dimensionality, collinearity, missing data, and noise [16].

The objective of this study is to illustrate how multivariate regression method, PLSR, can be used for modelling and predicting the energy consumption of a cabin building based on climate variables. We will discuss the variables using PLSR methodologies for understanding the qualitative information and variable relationships between predictors and responses and, energy consumption optimization. The results from conventional, linear PLSR modelling will be used to estimate the amount of energy required to maintain the building at a pre-defined temperature setpoint.

The PLSR model can be used for saving space heating 
energy consumption by lowering the set temperature as much as possible when the building is not in use. Further, it is anticipated that the resulting model can be used as a simplified design tool for a BEMS to control the heating energy of the stipulated building. Moreover, as mentioned earlier, it can be combined with dynamic models to control the heating and to estimate the heating time of the building which can be used to determine the heating time before occupant arrival.

\section{EXPERIMENTS}

The building used for experiments is a two-storied cabin building located in Lillehammer, Norway which was built in 1994. Each floor of the building has separate entrances from the outside. The building is not ventilated by mechanical means unless the doors and windows are open for natural ventilation. A sketch of the two floors of the building is shown in Fig. 1. It depicts the size of the building, locations of heaters and locations of inside and outside temperature and humidity sensors.
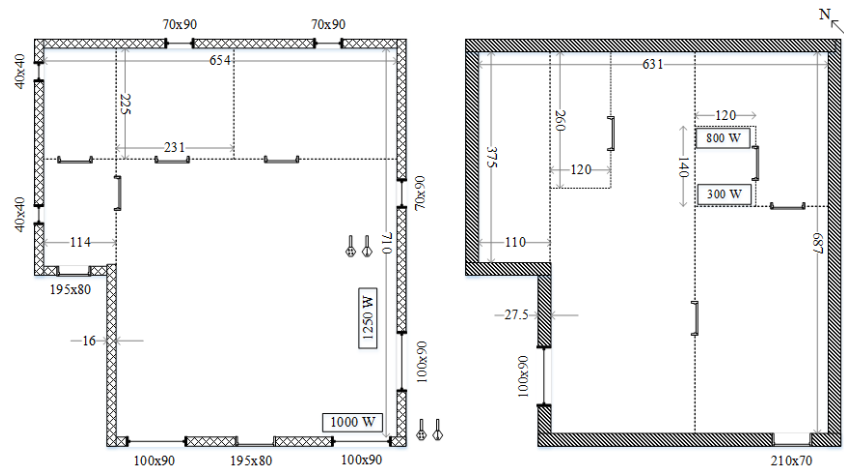

Fig. 1. Sketch of the residential building used for experiments - First floor and basement. The first floor has sensors for temperature, humidity and pressure measurements.

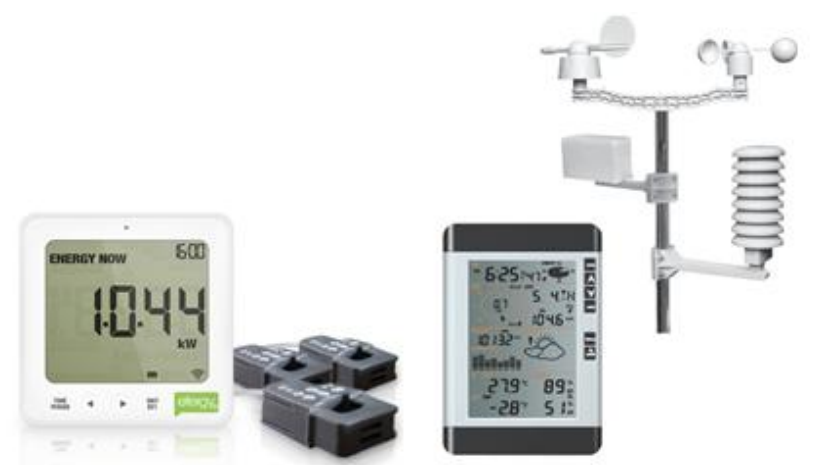

Fig. 2. The first Fig. 1 shows the two units of the Efergy e 2 power sensor and the second Fig. 1 shows the indoor unit and the outdoor unit of the weather station. The indoor unit contains temperature, humidity and pressure sensors with the display unit. The outdoor unit is for wind speed, direction and rainfall measurements.

The building is a cabin, occupied only occasionally in the weekends. However, the heaters are operating continuously during the cold winter periods as low temperatures can lead to freezing of water sources inside the building. The only heating sources in the building are four heaters and a personal computer, used for data logging. Two heaters, $1000 \mathrm{~W}$ and $1250 \mathrm{~W}$ are in operation on the first floor, and both heaters in the basement are also in operation. Heaters are controlled by on-off switches having a set temperature of $7^{0} \mathrm{C}$ with an operating band of $\pm 0.5^{\circ} \mathrm{C}$. The computer is in the basement and generate approximately $100 \mathrm{~W}$.

Our primary goal is to develop a multivariate regression model that can predict the total energy consumption of the building based on weather conditions. Hence, the response variable (Y) is the total energy consumption of the building in $\mathrm{kWh}$. It is measured using a wireless electricity monitor (efergy e2) as shown to the left in Fig. 2. This sensor is more than $90 \%$ accurate, and it provides the hourly average energy consumption of the building. A weather station shown to the right in Fig. 2 is used to measure the predictor variables (X). The measurements from the weather station are also logged in one-hour sampling intervals. Table I shows the measurements obtained from the weather station. The X data set comprises of the weather station data.

The data is collected from 27-09-2013 to 14-04-2014 (Data set A) and from 09-10-2014 to 26-12-2014 (Data set B). The raw X measurements form a matrix of $5901 \times 14$, and raw $\mathrm{Y}$ measurements form a vector of $5901 \times 1$. Out of the measurements, Rel P, Gust, Dew P, Wind C, WL and GL are estimated on-line from the raw measurements. Gust is the highest wind speed occurred during the past hour. Wind level and gust level are two empirical measures which relates the wind and gust speeds to observed conditions at sea or land, which is referred as the Beaufort Scale.

\begin{tabular}{ll} 
TABLE I: MEASUREMENTS OBTAINED FROM THE WEATHER STATION \\
\hline \hline Measurement type & Variable notification \\
\hline Inside temperature $\left({ }^{0} \mathrm{C}\right)$ & T In \\
Outside temperature $\left({ }^{0} \mathrm{C}\right)$ & T Out \\
Inside humidity & RH In \\
Outside humidity & RH Out \\
Absolute pressure (bar $)$ & Abs P \\
Relative pressure $($ bar $)$ & Rel P \\
Wind speed $(\mathrm{km} / \mathrm{h})$ & Wind \\
Gust speed $(\mathrm{km} / \mathrm{h})$ & Gust \\
Wind direction $(\mathrm{radians})$ & Dir \\
Dew point $\left({ }^{0} \mathrm{C}\right)$ & Dew P \\
Wind chill $\left({ }^{0} \mathrm{C}\right)$ & Wind C \\
Hourly rainfall $(\mathrm{mm})$ & RF \\
Wind level $(\mathrm{bft})$ & WL \\
Gust level $(\mathrm{bft})$ & GL \\
\hline \hline
\end{tabular}

\section{Multivariate Data AnAlysis AND MODEL DEVELOPMENT}

In situations where a complex data analysis requires, such as building energy optimization, univariate methods that are dealing with only one variable at a time are insufficient for a broad analysis [18]. Complex and large process data sets are often evaluated using multivariate projection methods such as Principal Component Analysis (PCA), PCR and PLSR [19]. The problems encountered in data analysis related to building energy optimization such as dimensionality, correlations, missing data, more variables-few observations and noise can be handled using comprehensive data analysis tools such as multivariate analysis [16]. PLSR differs from PCR by using the Y-variables actively during the bilinear decomposition of $\mathrm{X}$ and hence reduces the impact of large, but irrelevant $\mathrm{X}$-variations in the regression modelling [20]. 
It is also a well-known technology that can be used to find relationships between building energy related parameters. The PLSR approach is tested on the test building, using the space heating energy consumption as $\mathrm{Y}$ variable and weather data as $\mathrm{X}$ variable. The following sections explain the tasks carried out to approach the PLSR model for power consumption.

\section{A. Preprocessing of the Data}

The measurements obtained from the weather station comprise noise, which requires pre-processing of the data before model calibration. Hence, the X-measurements are first smoothed using moving average method with a segment size of three. Since the aim is to develop a multivariate model that can predict the unoccupied energy consumption, only data from the unoccupied periods are used. The Y measurement require no smoothing.

The heaters are controlled with an on-off controller at a setpoint of $7^{0} \mathrm{C}$. The heater is off while the inside temperature is equal or above $7^{0} \mathrm{C}$ representing zero energy consumption. The energy consumption data shows a clear non-linear behaviour owing to this reason. This phenomenon reduces the accuracy of the model and, therefore, all zero energy samples are removed from the dataset. Samples found to have high inside temperatures are also omitted because they are highly affected by other factors such as sun irradiation which is not measured in this work. The lack of ventilation and relatively large windows to the south indicates that the cabin receives a significant amount of solar irradiation. Further, only sub-zero outside temperatures are interested in this model development as they exemplify colder conditions and hence considerable energy consumption. After removing the outliers, the final data set consists of 2660 samples and was used for PLSR calibration.

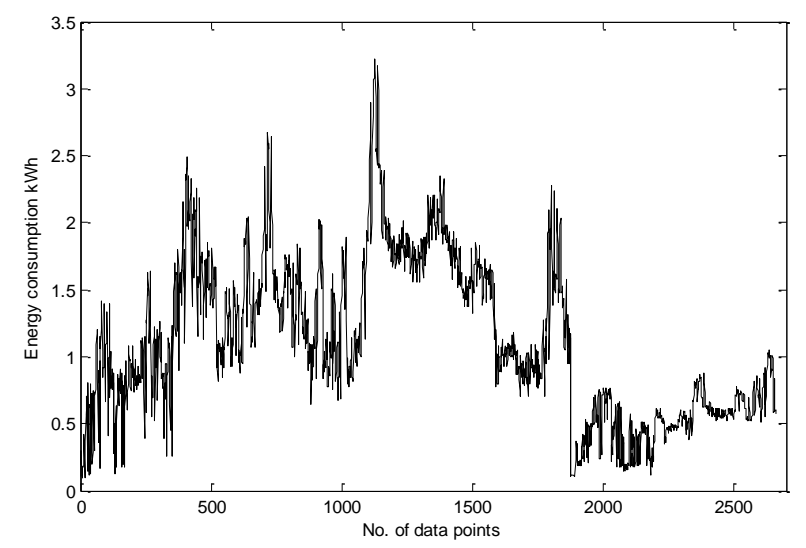

Fig. 3. Variation of the response variable. The vertical axis represents the hourly average energy consumption in $\mathrm{kWh}$, and horizontal axis depicts the number of samples.

The time series plot of the response variable after pre-processing is presented in Fig. 3. The energy consumption has a range from $0.1 \mathrm{kWh}$ to $3.22 \mathrm{~kW} \mathrm{~h}$. The levels of energy are generally lower at the end of the sampling period than the rest. This corresponds to the high outside temperatures of the samples collected in March and April in data set B.

\section{B. Data for Calibration and Validation}

Test set validation is the best method if there are enough objects and if the test set is representative [18]. Cross-validation is used if there are not enough objects for a separate test set or when it is not possible to pick a representative test set [18]. Leverage correction is an approximate validation and can be used only in the first runs to get an impression on how good the model is [18].

The test set validation is used to validate the PLSR model. One-third of the parent samples (887 samples) was selected as the test set. The remaining 1773 samples calibrate the PLSR model.

\section{PLSR Model Development}

The data set was centered and scaled to unit variance. The mean and standard deviation of all predictor and target variables for pre-processed observations are presented in Fig. 4. According to the figure, the average rainfall is nearly zero. The samples are basically collected during cold winter periods where the outside temperature is less than $0^{\circ} \mathrm{C}$. During this period the precipitation is in the form of snow. The solid form of water is not measured by the rainfall sensor and rainfall is often $0 \mathrm{~mm}$ for more than $99 \%$ of the measurements. Therefore, the RF variable has lack of variation as presented. Further, it is observed from the loading and loading weights plots that RF loadings on the first four Partial Least Squares (PLS) components are very small. The rainfall was therefore removed in the final PLSR model development.

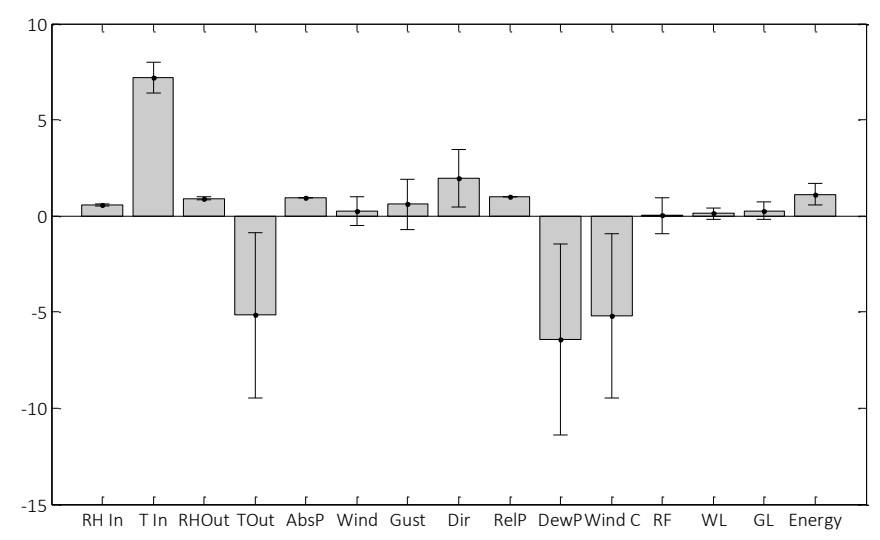

Fig. 4. The mean and standard deviations of the predictor (Table 1) and target variables for pre-processed observations.

\section{RESUlts}

In this section, the correlation of the 13-predictor variables with the energy consumption is described utilizing conventional PLSR modeling. The explained Y-variance of the model is $84 \%$ using $65 \%$ of the $\mathrm{X}$-variation for three components.

The score plot of the first two components are presented in Fig.5. Along PLS component 1, the energy consumption values vary from low to high. The lowest energy consumptions are highlighted as "a" and the highest energy consumptions are highlighted as "b". The points marked with "c" represents particularly higher wind and gust speeds.

The loading weights plot is shown in Fig. 6. The variables "T Out" and "Wind C" are positively correlated and have almost similar loading weights. In the Fig.6, they overlap each other and contributes strongly to the first PLS 
component, but not significantly to the second component. Further, they are negatively correlated with the energy consumption. That means, lower the outside temperature or wind chill, higher the energy consumption. "RH In" is important for both first and second PLS components as it contributes to higher loading weights on both axes. Highest indoor humidity samples are observed at the lower left corner of the score plot. The loadings for the inside temperature on both axes are small. This is because the T In is kept close to a constant temperature at $7^{0} \mathrm{C}$ by the on-off controllers. "RH Out" also contributes significantly to the first PLS component. At the beginning of the study, we believed that "RH Out" has a minimum contribution to the model because the building is not ventilated. However, it turned out that "RH Out" is an influential variable for energy consumption. "Abs P" and "Rel P" variables are having very close relationship. However, "Rel P" is different from the "Abs P" approximately 0.04 bar. They are highly correlated and have a correlation coefficient of 0.962 . The comparison of Figures 5 and 6 , shows that the values of variables related to wind speed (Wind, Gust,WL, GL) are high for data set c.

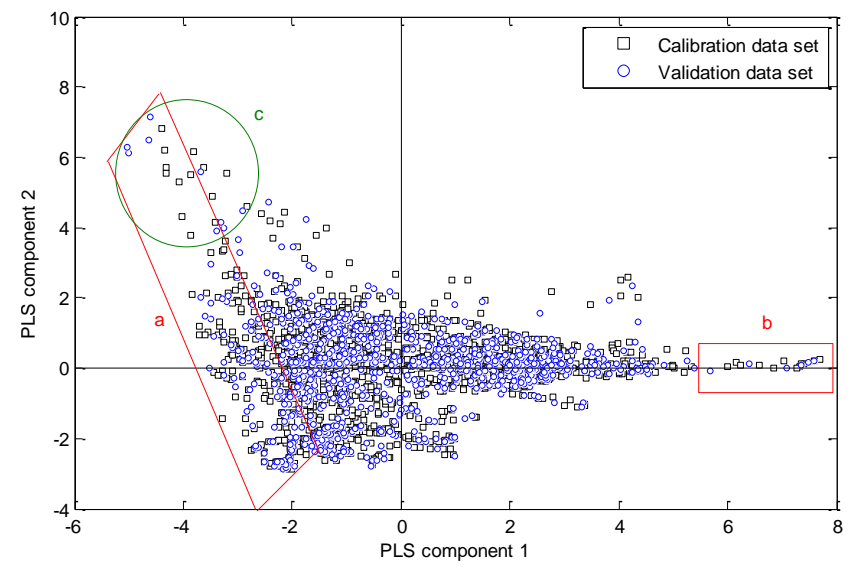

Fig. 5. Score plot of the first two components of the PLSR model. The calibration and validation data sets are distinguished.

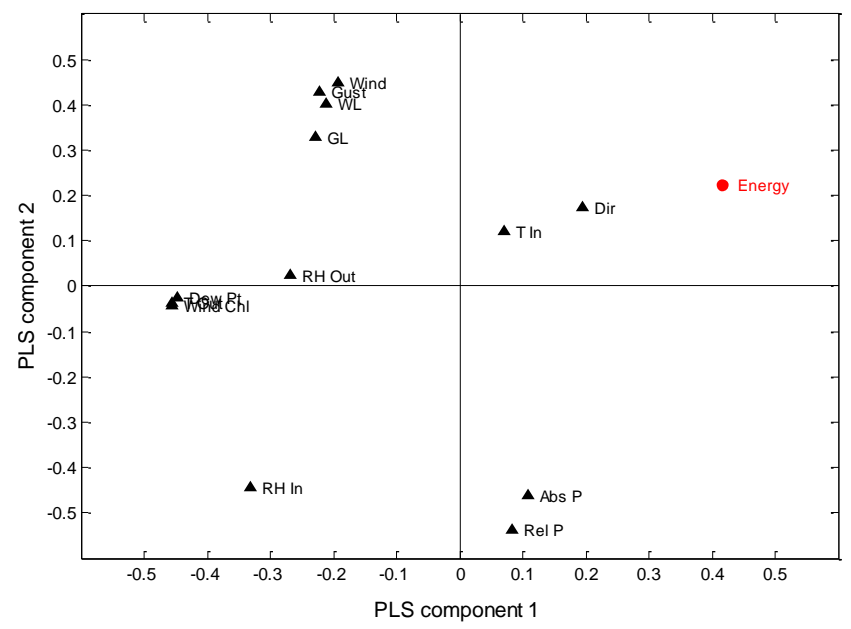

Fig. 6. PLS loading weights plot (PLS Component 1 Vs PLS Component 2). The Y variable, energy consumption, is highlighted.

The residual $\mathrm{Y}$ validation variance plot is of high importance in determining the optimal number of components of the PLSR model. The residual Y validation variance is illustrated in Fig. 7. The PLS-component 1 takes care of the largest fraction of the Y-variance modelled and decreases with the rest of the components. Only $33 \%$ of the $\mathrm{X}$-variance is modelled to predict $72 \%$ of $\mathrm{Y}$ at PLS component 1. For the second and third components, the explained $\mathrm{X}$ variance is $17 \%$ and $15 \%$ respectively, while the corresponding $\mathrm{Y}$-variance is $8 \%$ and $4 \%$. According to the figure, the prediction error starts a flat disposition at four PLS components, and it is also the first minimum of the graph. The predicted Y variance at the fourth component is only $1 \%$ using $14 \%$ of $\mathrm{X}$ and after the fourth component prediction is zero. Considering the facts, a PLSR model of three PLS components is used to estimate the energy consumption. From Fig. 8, it is also observed that $34.5 \%$ of the $\mathrm{X}$ variance is irrelevant for predicting the energy of the building.

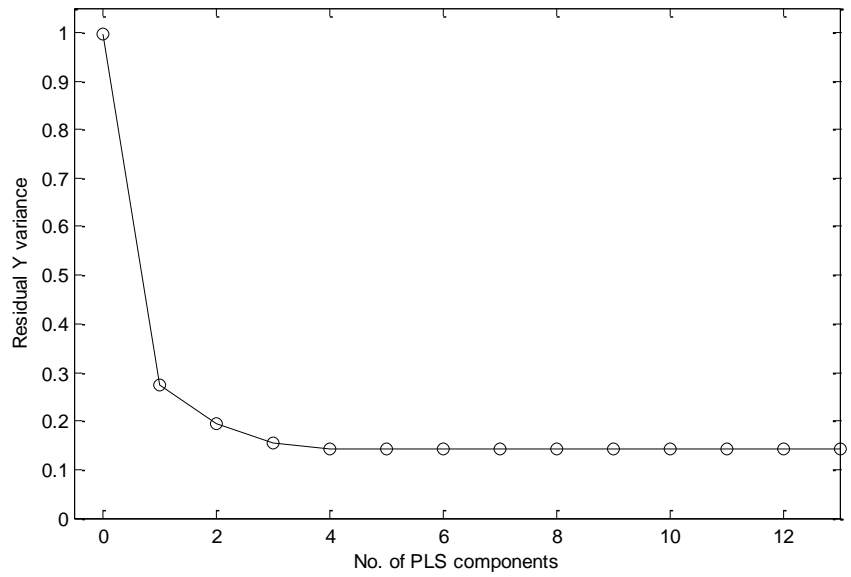

Fig. 7. The residual validation variance of power consumption variable. The predictions from first four components are $72 \%, 8 \%, 4 \%$ and $1 \%$.

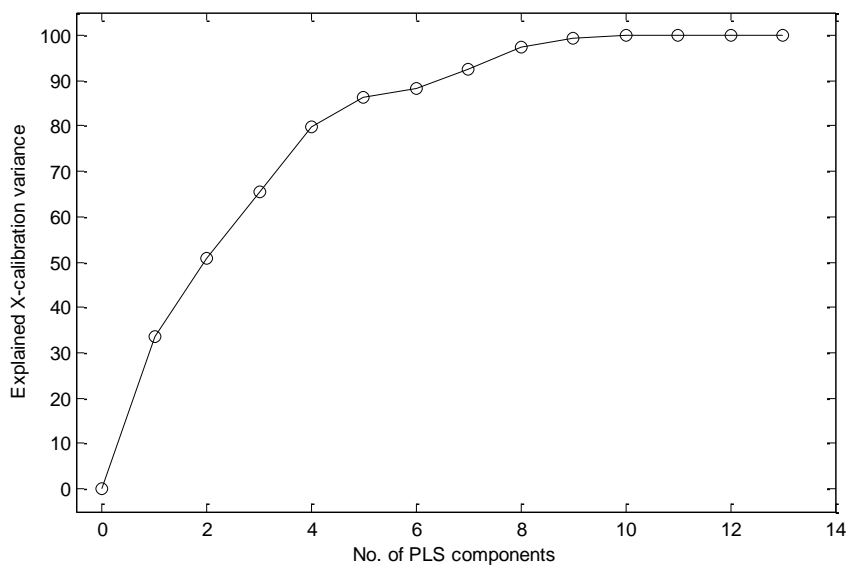

Fig. 8. The total X-calibration variance. The total explained variance from first three PLS components is $65.5 \%$.

The relationship between observed and estimated energy consumption is plotted in Fig. 9. The target line and the regression line are also presented. The root mean square error of calibration and prediction is $0.231389 \mathrm{kWh}$ and 0.230849 $\mathrm{kW} \mathrm{h}$ respectively. According to Fig. 9, the predictions has less accuracy at high energy consumptions and low energy consumptions close to zero. Energy consumptions higher than $\approx 1.5 \mathrm{kWh}$ are predicted as lower consumptions and the consumptions less than $\approx 1 \mathrm{kWh}$ are predicted as higher consumptions. The regression line closely follows the target line in the $1 \mathrm{kWh}-1.5 \mathrm{kWh}$ region, where highly accurate predictions can be observed. The samples to the centre of the score plot are nicely transformed to the energy consumption by the PLSR model. There are total of 1256 samples where Energy consumption<1 kWh, 819 samples where Energy 
consumption $>1.5 \mathrm{kWh}$ and 585 samples lying in between. Increasing the number of samples collected at high power consumptions may reduce the deviation from the target.

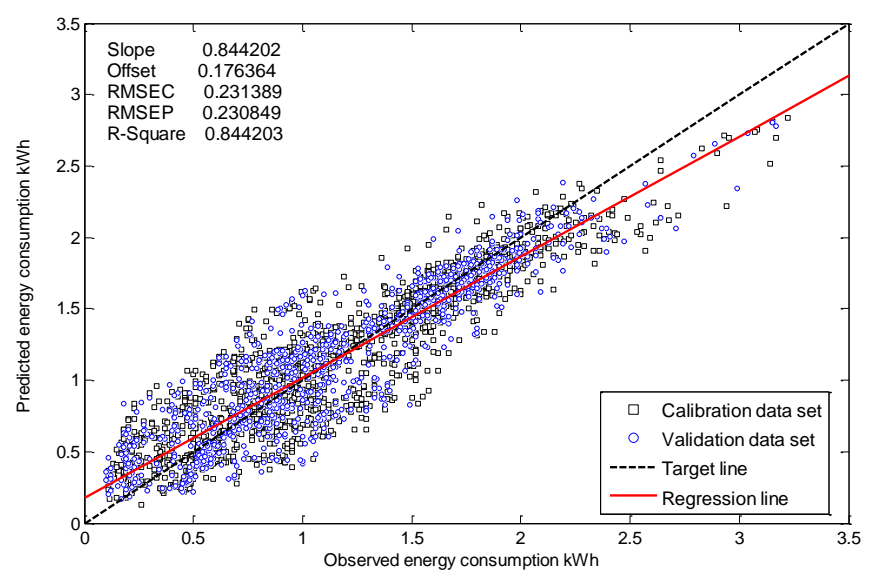

Fig. 9. The plot of the relationship between predicted Energy consumption and observed Energy consumption of PLS model.
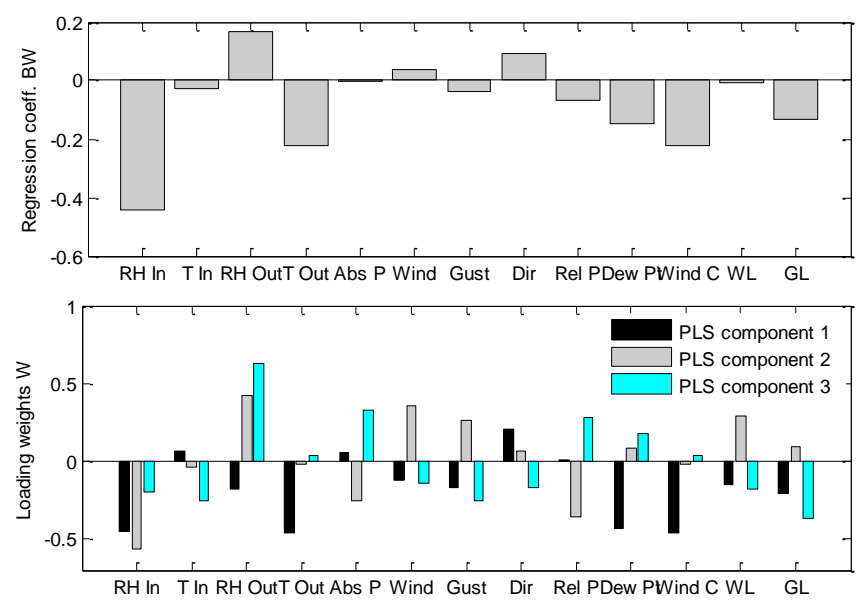

Fig. 10. Graph of weighted regression coefficients and loading weights of the variables. Loading weights are presented for first four consecutive components.

TABLE II: THE PLS MODEL RAW REGRESSION COEFFICIENTS FOR THE ENERGY CONSUMPTION OF THE BUILDING

\begin{tabular}{ll}
\hline \hline Variables & Values \\
\hline RH In & -4.107 \\
T In & $-2.090 \mathrm{e}-2$ \\
RH Out & 1.266 \\
T Out & $-3.050 \mathrm{e}-2$ \\
Abs P & $-4.525 \mathrm{e}-2$ \\
Wind & $3.446 \mathrm{e}-2$ \\
Gust & $-1.775 \mathrm{e}-2$ \\
Dir & $3.652 \mathrm{e}-2$ \\
Rel P & -2.892 \\
Dew P & $-1.754 \mathrm{e}-2$ \\
Wind C & $-3.078 \mathrm{e}-2$ \\
WL & $-1.464 \mathrm{e}-2$ \\
GL & -0.179 \\
\hline \hline
\end{tabular}

The weighted regression coefficients and the loading weights for each variable of the PLSR model are shown in Fig.10. "RH In" has the highest weighted regression coefficient while "Abs P" has the lowest. Based on the combinations of the inputs, the model coefficients may or may not have physical significance [2]. The raw regression coefficients that can be used to predict the future energy consumptions from the raw $\mathrm{X}$ variables are tabulated in Table II. Weighted PLSR model constant $\left(\mathrm{B}_{\mathrm{OW}}\right)$ is 0.601938 and raw PLSR model constant $\left(\mathrm{B}_{\mathrm{O}}\right)$ is 0.352969 . The most important variables for the prediction are RH In, T Out, Wind $\mathrm{C}$ and Dew Pt. "RH In" has high loading weights on both first two PLS components while the rest influential variables are dominating in the first component.

\section{DISCUSSION}

As indicated in this study, multivariate analysis by PLSR results in a model that predicts the building energy consumption. The variables were sufficiently informative to predict the space heating energy requirement with root mean square error of $0.23 \mathrm{kWh}$ on an hourly basis. The percentage RMSEC of the calibrated model is approximately $20 \%$ of the total Y-range. Typically, models are declared to be used if they produce RMSEs within $\pm 30 \%$ when using hourly data [21]. This means that the model developed has an acceptable accuracy when three PCs are used. The model described with even only one component $(\approx 26 \%$ RMSE) returns the required accuracy.

Moreover, the model enabled the identification of few influential weather variables such as outdoor temperature; dew point; wind chill and indoor relative humidity. The main influencing factor for high energy consumption is outdoor temperature. Kissock et al. identified that the space heating energy consumption in many buildings such as residences and small commercial buildings increases as outdoor air temperature decreases below some balance-point temperature $^{1}$ [22]. They suggest that the energy consumption can be adequately described by parameterized models that relate energy consumption and outside air temperature which is verified by the developed model as well. Countermeasures should be taken to reduce the effect of temperature by having proper insulation materials for the building envelope. Comparing the climate statistics for last 110 years for the province where test building is located, one finds that the average temperature in winter is $-8.4^{0} \mathrm{C}$. The relevant power consumptions when the outdoor temperature is around $-8^{0} \mathrm{C}$ is within $1.5-2 \mathrm{kWh}$ range. The predictions have a good fit within these limits, and, therefore, we believe that the model can be used without major issues in the future. However, the model is calibrated for an outdoor temperature interval from $0^{0} \mathrm{C}$ to $-24.5^{\circ} \mathrm{C}$ and deviations from these limits will require recalibration of the model.

The developed PLSR model for hourly energy consumption prediction is accurate enough, simple, easy to use and fast. Further, the model can simply be converted to a programming language like C\# or Java. Hence, it satisfies the requirements for integration in BEMS. Therefore, it can be used as a simplified design tool to on-line control the heating energy of the specified building. It is also obvious that the model can be combined with a dynamic model of the building to estimate the heating time that can be useful for control and energy saving measures.

Even though, statistical models are relatively easy to develop, there are obvious drawbacks. Lack of flexibility and

\footnotetext{
${ }^{1}$ The temperature at which the internal heat gains balance the heat loss through building envelope.
} 
inaccuracy are two main limitations of these models. Further, PLSR models are not so efficient in modelling non-linear systems. For example, in the specified problem there were samples that had zero power consumption because of the on-off controlling of heaters. The total dataset with these non-linear samples did not provide an accurate enough model to predict the power consumption for all occurrences. Hence, we had to filter out those samples before developing the PLSR model. In such situations, Artificial Neural Networks and Support Vector Machines may be good options for assessing complex building energy predictions [23].

\section{CONCLUSION}

This report presents an approach to utilize weather data for space heating energy prediction and identification of driving weather variables relevant to energy use. PLSR modelling was used to relate the weather data to the target variable. For the simplification of the model while achieving acceptable accuracy first three PLS components were used. To find the most influential variables, the PLS loadings and regression coefficients were analyzed. The suggested approach was tested on a two storey cabin building located close to Lillehammer, Norway.

In summary, we infer that the collected weather variables were sufficiently informative to predict the energy consumption load during the cold winter period. The consumption is mainly influenced by the outdoor temperature, dew point, wind chill and indoor humidity. The RMSEP of the developed model is approximately $20 \%$, and it is in the acceptable range according to the ASHRAE guidelines. The suggested approach used in this study can be used as an additional virtual energy management tool for the specified building. It is useful to save the energy of the cabin when not in use. Further advantages of the model are that the possibility of utilization for on-line control in BEMS and integration with building dynamic model to estimate the heating time.

\section{REFERENCES}

[1] L. P. Lombard, J. Ortiz, and C. Pout, "A review on buildings energy consumption information," Energy and Buildings, 2008, vol. 40, no. 3 , pp. 394-398.

[2] L. G. Swan and V. I. Ugursal, "Modeling of end-use energy consumption in the residential sector: A review of modeling techniques," Renewable and Sustainable Energy Reviews, 2009, vol. 13, no. 8, pp. 1819-1835.

[3] C. A. Balaras et al., "European residential buildings and empirical assessment of the Hellenic building stock, energy consumption, emissions and potential energy savings," Building and Environment, vol. 42, no. 3, pp. 1298-1314, 2007.

[4] B. Bergesen et al., "Energy consumption 2012 - household energy consumption I.H. magnussen," Norwegian Water Resources and Energy Directorate.

[5] D. W. U. Perera, C. Pfeiffer, and N. O. Skeie, "Modelling the heat dynamics of a residential building unit: Application to Norwegian buildings," Modeling, Identification and Control, 2014, vol. 35, no. 1, pp. 43-57.

[6] G. S. Virk, J. M. Cheung, and D. L. Loveday, "Development adaptive control techniques for BEMs," presented at International Conference on Control '91, 1991.

[7] W. Perera, C. F. Pfeiffer, and N. O. Skeie, "Modeling and simulation of multi-zone buildings for better control," presented at the 55th Conference on Simulation and Modelling, 2014, Aalborg, Denmark: Linköping University Electronic Press.
[8] D. W. U. Perera, C. Pfeiffer, and N. O. Skeie, "Control of temperature and energy consumption in buildings," International Journal of Energy and Environment, 2014, vol. 5, no. 4, pp. 471-484.

[9] M. Bauer and J. L. Scartezzini, "A simplified correlation method accounting for heating and cooling loads in energy-efficient buildings," Energy and Buildings, 1998, vol. 27, no. 2, pp. 147-154.

[10] J. Pfafferott, S. Herkel, and J. Wapler, "Thermal building behaviour in summer: long-term data evaluation using simplified models," Energy and Buildings, 2005, vol. 37, no. 8, pp. 844-852.

[11] K. E. Westergren, H. Högberg, and U. Norlén, "Monitoring energy consumption in single-family houses," Energy and Buildings, 1999. vol. 29 , no. 3 , pp. $247-257$.

[12] M. R. Braun, H. Altan, and S. B. M. Beck, "Using regression analysis to predict the future energy consumption of a supermarket in the UK," Applied Energy, 2014, vol. 130, pp. 305-313.

[13] J. C. Lam, K. K. W. Wan, D. Liu, and C. L. Tsang, "Multiple regression models for energy use in air-conditioned office buildings in different climates," Energy Conversion Management, vol. 51, 2010, pp. 2692--2697.

[14] S. Y. Zhou and N. Z, "Multiple regression models for energy consumption of office buildings in different climates in China," Front. Energy, 2013, vol. 7, no. 1, pp. 103-110.

[15] N. Djuric and V. Novakovic, "Identifying important variables of energy use in low energy office building by using multivariate analysis," Energy and Buildings, 2012, vol. 45, pp. 91-98.

[16] T. Olofsson, S. Andersson, and J. U. Sjögren, "Building energy parameter investigations based on multivariate analysis," Energy and Buildings, 2009, vol. 41, no. 1, pp. 71-80.

[17] J. F. MacGregor and T. Kourti, "Statistical process control of multivariate processes," Control Engineering Practice, 1995, vol. 3, no. 3, pp. 403-414.

[18] K. H. Esbensen et al., "Multivariate data analysis - In practice: An introduction to multivariate data analysis and experimental design," Camo Process AS, 2002.

[19] L. Eriksson et al., "Multivariate process monitoring of a newsprint mill, application to modelling and predicting COD load resulting from de-inking of recycled paper," Journal of Chemometrics, 2001, vol. 15 , no. 4, pp. 337-352.

[20] H. Martens and T. Næs, Multivariate Calibration, 1989, Chichester: Wiley.

[21] Measurement of Energy and Demand Savings, Guideline, Ashrae, 2002.

[22] J. K. Kissock, J. S. Haberl, and D. E. Claridge, Inverse Modeling Toolkit: Numerical Algorithms, Ashrae, 2003.

[23] H. X. Zha, and F. Magoulès, "A review on the prediction of building energy consumption," Renewable and Sustainable Energy Reviews, vol. 4, pp. 570-578, July 1993.

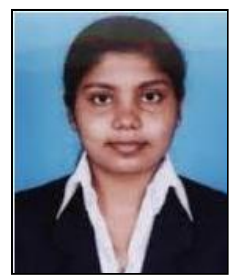

D. Wathsala Upamali Perera was born in Colombo, SriLanka in 1984 and has a MSc degree in energy and environmental technology from Telemark University College (TUC), Porsgrunn, Norway in 2012 and has a BSc degree in chemical and process engineering from University of Moratuwa (UOM), SriLanka in 2009.

She is presently pursuing her Ph.D at TUC since 2012, and her topic is related to mathematical models for real-time estimation of space heating in buildings. She has work experience as a process development and compliance engineer in Silueta (pvt) Ltd, SriLanka (2009-2010) and process engineer in CPC Agrifoods Ltd, SriLanka (2007-2008).

Mrs. Perera's research interests are energy efficient buildings, modelling, simulation, and heat transfer processes.

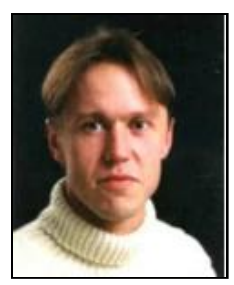

Maths Halstensen has a $\mathrm{PhD}$ degree in process monitoring from the Norwegian University of Science and Technology in 2001 and has a MSc degree in process automation from Telemark University College (TUC) in 1997 and a BSc degree in industrial electronics from Gjøvik University College in 1995 $\mathrm{He}$ is an Associate professor in TUC since 2002 and teaches chemometrics, supervises $\mathrm{MSc}$ and $\mathrm{PhD}$ students.

Prof. Halstensens's main research interests include chemometrics, process analytical technologies \& process monitoring. 


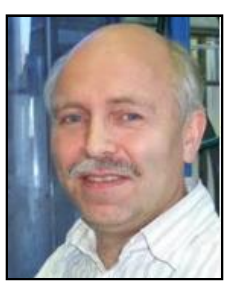

Nils-Olav Skeie was born in 1959 in Norway and held a master of science in cybernetic from Norwegian University of Science and Technology (NTNU) from 1985 and a PhD in cybernetics from NTNU and Telemark University College (TUC) from 2008.

He has industrial experience from 1985 to 2003 in several companies working mainly with system design, both software and hardware development. The aviation and maritime sectors.

He has been an associate professor at TUC since 2008 and is teaching in measurement techniques, software design and system design on B.Sc. and M.Sc. levels. He supervises B.Sc., M.Sc. and PhD students.

His main research areas are smart buildings with focus on energy usage and welfare systems, soft sensors, sensor networks, and level measurements. 